\title{
Dental treatment recommendations and coronavirus disease 19 (COVID-19)
}

\author{
Siebert T, Janickova M, Stenchlakova B, Statelova D \\ Department of Stomatology and Maxillofacial Surgery, Jessenius Faculty of Medicine in Martin, Comenius \\ University in Bratislava, University Hospital in Martin, Slovakia. dagmar.statelova@uniba.sk
}

\begin{abstract}
Health is a state of complete physical, mental and social well-being. The outbreak of coronavirus disease 2019 (COVID-19) in the area of Wuhan, China, has evolved rapidly into a public health crisis and has spread exponentially to other parts of the world.

There is strong evidence that this novel coronavirus is similar to coronavirus species found in bats and potentially pangolins, confirming the zoonotic nature of this new cross-species virus-mediated disease. Dentists provide support and management for patients. They proceed in accordance with the current guidelines of the government of each country as well as with the valid standards and preventive, diagnostic and therapeutic procedures for COVID-19.

This article mainly focuses on the recommended methods in dental medicine designed to protect patients and healthcare professionals (Tab. 2, Ref. 29). Text in PDF www.elis.sk

KEY WORDS: coronavirus, COVID-19, dental strategies, dental treatment recommendations.
\end{abstract}

\section{Introduction}

"Health is a state of complete physical, mental and social well-being and not merely the absence of disease or infirmity" (1). Dental plaque is the most important cause of various forms of dental caries and periodontitis, while its structure plays a significant role in the process. Thus, not only dental plaque but also other factors such as age, sex, nutrition and sociological aspects are involved in the etiology and progression of tooth and periodontium destruction. After dental caries, the diseases of periodontium are the second most common condition that dentists encounter in their practice. In accordance with the above-cited definition of health by the World Health Organization, the periodontal health should be defined as a state free from inflammatory periodontal disease that allows an individual to function normally and not suffer any consequences (mental or physical) as a result of past disease (2).

The outbreak of coronavirus disease in 2019 (COVID-19) in the area of Wuhan, China, has evolved rapidly into a public health crisis and has spread exponentially to other parts of the world $(3,4)$.

Department of Stomatology and Maxillofacial Surgery, Jessenius Faculty of Medicine in Martin, Comenius University in Bratislava, University Hospital in Martin, Slovakia

Address for correspondence: D. Statelova, MD, PhD, Department of Stomatology and Maxillofacial Surgery, Jessenius Faculty of Medicine in Martin, Comenius University in Bratislava, University Hospital in Martin, Kollarova 2, SK-036 01 Martin, Slovakia.

Phone: +421.905859569

Acknowledgements: The authors claim to have no financial interest in any company or any of the products mentioned in this article.
The novel coronavirus belongs to a family of single-stranded RNA viruses known as Coronaviridae (5). This family of viruses is known to be zoonotic or transmitted from animals to humans. These include severe acute respiratory syndrome caused by coronavirus (SARS-CoV), first identified in 2002, and Middle East respiratory syndrome caused by coronavirus (MERS-CoV), first identified in 2012 (6). On January 30, 2020, the World Health Organization (WHO) declared a public health emergency caused by the rampant spread of SARS-CoV-2 and its associated disease (COVID-19) with overall mortality rate then known to be as high as $3.4 \%(7,8)$. According to the WHO situation report on COVID-19 (updated as of April 30, 2020), there were more than 3,090,445 confirmed and reported cases and 217,769 deaths worldwide, and these numbers continued to increase (9). In Europe, 1,434,699 confirmed cases and 135,961 deaths were then reported (9).

During the COVID-19 pandemic, healthcare systems of most countries in the world have faced an unprecedented challenge regarding how to counteract the dramatic spread of the disease and how to simultaneously reduce its high case-fatality rate. Given the alarming global situation and rapidly evolving large-scale pandemic, there is an urgent need for effective strategies to prevent the spread of the disease and decrease its high case-fatality rate (10). The gravity of the situation requires the consideration of novel or unorthodox strategies to control the outbreak and high lethality of COVID-19 (11). Given the widespread transmission of SARS-CoV-2 and reports of its spread to healthcare providers, dental professionals are at high risk for nosocomial infection and can become potential carriers of the disease $(4,11,12)$.

These risks can be attributed to the unique nature of dental interventions, which include aerosol generation, handling of 
sharps, and proximity of the provider to the patient's oropharyngeal region (4).

In this article, we summarize recommendations for managing, diagnosing and treating dental patients during the worldwide pandemic of COVID-19. This information is as of April 2020.

\section{Dental treatment recommendations}

Asymptomatic patients of COVID-19 can act as "carriers" and serve as reservoirs for infection reemergence (4). Although SARS-CoV-2 is known to be highly transmissible when patients are the most symptomatic, it is noteworthy that the incubation period can range from 0 to 24 days; therefore, the transmission can occur before any symptoms are apparent $(13,14,15)$. Patients with COVID-19 usually present with clinical symptoms of fever, dry cough, and myalgia. In addition, less obvious symptoms such as nausea, diarrhea, reduced sense of smell (hyposmia), and abnormal taste sensation (dysgeusia) have also been reported $(4,16)$. Dentists primarily provide telephone support and patient management during standard dental practice hours. They proceed in accordance with the current wording of the Ministry of Health guidelines and valid standard, preventive, diagnostic and therapeutic procedures regarding COVID-19. On a daily basis, they follow the guidelines, decisions and instructions of the Public Health Authority of the national country, self-government bodies, and nation's Chief Expert of the Ministry of Health for dental medicine. Dentists only treat patients with urgent problems, preferably in the morning hours. For a patient who does not have severe problems, dentists recommend only symptomatic therapy and prescribe an e-prescription if necessary. They also recommend a procedure via telephone, email or SMS consultation in the event of deteriorating health that requires an evaluation of the patients. The dentists keep records of their communications with patients as well as of their recommendations within the patient's medical documentation. In suspected or confirmed cases of COVID-19 infections requiring urgent dental care for conditions such as tooth pain and/or swelling, pharmacologic management in the form of antibiotics and/ or analgesics is an alternative. This approach may offer a symptomatic relief and will provide dentists sufficient time to either refer the patient to a specialist or deliver dental care with all appropriate measures in place to prevent the spread of infection (4). In a dental ambulance, patients should be encouraged to wear a surgical mask and follow proper respiratory hygiene such as covering the mouth and nose with a tissue before coughing and sneezing and then discarding the tissue (17).

If necessary, the treating dentist will check the patient for suspected COVID-19 by measuring the patient's body temperature with a contactless thermometer and conducting an anamnestic interview, supported by an affidavit in form of a questionnaire designed to examine facts as follows:

(a) Patient's travel and medical history,

(b) Signs of respiratory disease,

(c) Possible contact with an infected or quarantined person.

The patients confirm their answers to questions posed in the questionnaire with their signature. If COVID-19 is suspected, the attending dentist is obliged to call the epidemiological office, where the patient will be referred to a designated quarantine center.

As per the Centers for Disease Control and Prevention guidelines, individuals with suspected COVID-19 infection should be seated in a separate, well-ventilated waiting area at least $6 \mathrm{ft}$ from unaffected patients seeking care (17). The dentist does not carry out planned interventions until further notice, including preventive examinations and dental hygiene procedures. Certain instances such as dentoalveolar trauma and progressive fascial space infection warrant emergency dental intervention (4). A limited number of employees work in the dental clinic including the attending dentist and nurse or dental assistant, or only the attending dentist works by himself, unless this is otherwise impossible due to the epidemiological situation. Ambulance staff maintain consistent hygiene and more frequent disinfection when operating the ambulance. The use of oxidizing agents and agents that reduce the surface tension of hydrophobic materials is recommended. All objects that may be affected by aerosols and are not directly related to the provision of dental-medical care (pens, mobile phones, radios, calculators, payment terminals, decorations, etc.) are removed from the rooms. It is necessary to ventilate regularly before the commencement of surgery and between individual procedures. Between individual procedures, it is necessary to use a germicidal radiator and precisely disinfect all surfaces. Magazines and other items that may cause cross-infection are removed from the waiting room. In the ambulance, it is recommended to have a stand-alone hanger for the patient's clothing. For epidemiological reasons, it is necessary to eliminate the interaction of patients in the ambulance. If the situation permits, the patients should not sit in the waiting room, and should only arrive after a previous telephone call from the car or outside. There should be no more people in the waiting room. The

Tab. 1. Personal protective equipment - PPE (adapted from Centers for Disease Control and Prevention recommendations for putting on and removing personal protective equipment for treating COVID-19 patients. From: https://www.cdc.gov/hai/pdfs/ppe/ppe-sequence.pdf.).

Personal Protective Equipment - PPE

GOWN

Fully cover torso from neck to knees, arms to ends of the wrists, and wrap around the back

Fasten in back of the neck and waist

RESPIRATOR + MASK

Respirator and mask for dental professionals

Mask for patients

Secure ties or elastic bands at the middle of the head and neck

Fit band to the bridge of the nose

Fit snug to the face and below the chin

Fit-check the respirator

GOGGLES OR FACE SHIELD

Place over face and eyes and adjust

GLOVES

Extend to cover the wrist of the isolation gown

Other recommendations

Keep hands away from the face

Limit surfaces touched

Change gloves when torn or heavily contaminated

Perform hand hygiene 
Tab. 2. Recommendations for dental management and treatment during COVID-19 (adapted from Ather et al. 2020).

\begin{tabular}{|c|c|c|}
\hline DIAGNOSIS & PRIMARY MANAGEMENT & SECONDARY MANAGEMENT \\
\hline $\begin{array}{l}\text { Symptomatic irreversible pulpitis } \\
\text { Symptomatic apical periodontitis }\end{array}$ & $\begin{array}{l}\text { Consideration for local anesthetic } \\
\text { Pain management } \\
\text { Antibiotics } \\
\text { Endodontic therapy }\end{array}$ & $\begin{array}{l}\text { For complications, call the Oral and Maxillofacial surgery } \\
\text { department for further instructions for a possible referral }\end{array}$ \\
\hline \multirow[t]{2}{*}{ Acute apical abscess } & $\begin{array}{l}\text { Intraoral swelling: } \\
\text { Local anesthetic } \\
\text { Incision and drainage } \\
\text { Antibiotics } \\
\text { Pain management }\end{array}$ & $\begin{array}{l}\text { For complications, call the Oral and Maxillofacial surgery } \\
\text { department for further instructions for a possible referral }\end{array}$ \\
\hline & $\begin{array}{l}\text { Extraoral swelling: } \\
\text { Antibiotics } \\
\text { Pain management } \\
\text { Local anesthetic }\end{array}$ & $\begin{array}{l}\text { Call the Oral and Maxillofacial surgery department for further } \\
\text { instructions for a possible referral }\end{array}$ \\
\hline Avulsion/luxation & $\begin{array}{l}\text { Replantation of the tooth } \\
\text { Antibiotics } \\
\text { Pain management }\end{array}$ & $\begin{array}{l}\text { Call the Oral and Maxillofacial surgery department for further } \\
\text { instructions for a possible referral }\end{array}$ \\
\hline Tooth fracture resulting in pain & $\begin{array}{l}\text { Vital pulp therapy } \\
\text { Endodontics therapy } \\
\text { Pain management }\end{array}$ & $\begin{array}{l}\text { Endodontics therapy } \\
\text { Call the Oral and Maxillofacial surgery department for further } \\
\text { instructions for a possible referral }\end{array}$ \\
\hline $\begin{array}{l}\text { Trauma involving facial bones, } \\
\text { potentially compromising the patient's } \\
\text { airway }\end{array}$ & Refer to Oral and Maxillofacial surgery & \\
\hline $\begin{array}{l}\text { Cellulitis or a diffuse soft tissue } \\
\text { bacterial infection }\end{array}$ & Refer to Oral and Maxillofacial surgery & \\
\hline
\end{tabular}

presence of persons should be reduced to a necessary minimum. It is advisable to keep as many doors open as possible to avoid cross-exposure through handles.

The attending dentist and assisting nurse or dental assistant shall be equipped with personal protective equipment (PPE) suitable to prevent exposure to aerosol-borne droplet respiratory infection (Tab. 1). These PPEs include respiratory masks, at least FFP3/N95, sealing, closed goggles and/or full-face, transparent shields, headgear, and long-sleeved clothing, as well as leg coverings, disposable gloves and leg warmers. If the attending dentist has a standard mask with an exhalation valve, it must be covered with a surgical mask to minimize the risk of potential air contamination if the dentist is an asymptomatic SARS-CoV-II virus carrier. Personal items such as watches, rings, chains, and bracelets should be kept away from the treatment room. Facial hair on men should be adjusted so that the respirator seals properly. Emphasis should be placed on the correct tightness of the mask, and contact with the outside of the mask should be limited. It is necessary to carefully separate infectious waste and to automate the dressing and undressing of protective equipment. During treatment, it is advisable to rinse the patient's mouth with $1 \%$ hydrogen peroxide solution before starting the procedure. Previous studies have shown that SARS-CoV and MERS-CoV were highly susceptible to a povidone mouth rinse (18).

Therefore, a preprocedural mouth rinse with $0.2 \%$ povidoneiodine might reduce the coronavirus load in the patient's saliva $(19,20)$.

Another alternative would be to use a $0.5-1 \%$ hydrogen peroxide mouth rinse, as it has nonspecific virucidal activity against coronaviruses (21).
Consequently, it is advisable to cover the face with a surgical sheet with an opening for the mouth to prevent aerosol transfer when breathing through the nose. If possible, always apply a dental dam as it will actively assist in aspirating to avoid saliva accumulation. Position the patient in a suitable posture that would prevent coughing. In case that a need to cool the rotary tools arises, dentists should try to use water without air to avoid aerosol formation, or additional cooling with saline from the assistance syringe. In order to prevent cross-contamination, the use of disposable (single-use) devices such as mouth mirrors, syringes, and blood pressure cuffs is encouraged (4). Extraoral imaging such as panoramic radiography or cone-beam computed tomographic imaging, should be used to avoid gag or cough reflexes that may occur with intraoral imaging. When intraoral imaging is mandated, sensors should be protected by a double barrier to prevent perforation and cross-contamination (22). In case surgical extraction is needed, we choose manual surgical instruments when possible.

SARS CoV-2 can remain viable in aerosols and survive up to 3 days on inanimate surfaces at room temperature, with a greater preference for humid conditions (23).

Therefore, clinic staff should make sure to disinfect inanimate surfaces using chemicals recently approved for COVID-19 and maintain a dry environment to curb the spread of SARS-CoV-228 (24). Dentists should minimize the use of ultrasonic instruments, high-speed handpieces, and 3-way syringes to reduce the risk of generating contaminated aerosols (4).

Recommendations for dental management and treatment during the COVID-19 pandemic are presented in Table 2. 


\section{Conclusion}

It is an indicated rule in dentistry that prevention is better, simpler, more effective, and cheaper than the treatment of a small or extensive destruction of the periodontal tissue of the tooth or the entire dentition of the patient.

However, due to weak patient adherence, visits for dental care are often cancelled, resulting in a lack of professional maintenance care, and increase in the potential for the recurrence of acute disease in the orofacial region. At the time of the COVID-19 pandemic, a patient ignoring dental care is all the more dangerous, especially for groups of the population who are severely at risk of disease and mortality. Any acute condition is a potential source of urgency for a patient to visit a dentist, even though he/she should adhere to strict epidemiological rules drafted by the appropriate government of each country.

As dentists, we have to learn from our general medicine colleagues at home and abroad, as they have much more experience associated with a large number of patients they have been already treating.

The analysis of the impact of these measures reveals the potential to reduce significantly the case-fatality rate in these large high-risk groups (10). A reduction in visits in dental ambulances seems to be vital to mitigate the infectious, psychological, and social impacts of the COVID-19 pandemic. The economic factor is relentless but cannot be superior to epidemiological factors at the time of the COVID-19 pandemic.

Some governments have suggested that the detection of antibodies to SARS-CoV-2, the virus that causes COVID-19, could serve as the basis for an "immunity passport" or "risk-free certificate" that would enable individuals to travel or return to work, assuming that they are protected against re-infection. There is currently no evidence that people who have recovered from $\mathrm{CO}$ VID-19 and have antibodies are protected from a second infection (25). WHO continues to review the evidence on antibody responses to SARS-CoV-2 infection $(25,26,27,28)$. Most of these studies show that people who have recovered from infection have antibodies to the virus. However, some of these people have very low levels of neutralizing antibodies in their blood, suggesting that cellular immunity may also be critical for recovery $(25,28)$. As of 24 April, 2020, no study has evaluated whether the presence of antibodies to SARS-CoV-2 confers immunity to subsequent infection by this virus in humans (28). At this point in the pandemic, there is not enough evidence about the effectiveness of antibodymediated immunity to guarantee the accuracy of an "immunity passport" or "risk-free certificate" (25).

Given the rapid spread of the pandemic, high mortality rate and the resulting paralysis of societal functioning, we believe the proposed measures have a favorable risk/benefit ratio and should be considered in scientifically-controlled settings (10). Of course, this strategy represents only a complementary approach to general anti-epidemic measures (masks, respirators, intensive hand hygiene), social distancing and mobility restrictions (29).

The proposed dental recommendations are of crucial importance to minimize the virus spread in the population, and to pro- tect dentists and healthy subjects, as well as those suspected of or vulnerable to COVID-19.

\section{References}

1. World Health Organization. Constitution of WHO: Principles http: // www.who.int/about/mission/en. Accessed March 26, 2018.

2. Lang NP, Bartold PM. Periodontal health. J Clin Periodontol 2018; 45 (Suppl 20): S9-S16. https: // doi.org/10.1111/jcpe.12936.

3. Dong E, Du H, Gardner L. An interactive web-based dashboard to track COVID-19 in real time. Lancet Infect Dis 2020. https: //doi.org/10.1016/ S1473-3099(20)30120-1.

4. Ather A, Patel B, Ruparel NB et al. Coronavirus Disease 19 (COVID-19): Implications for Clinical Dental Care. J Endodontics [online]. 2020 [cit. 2020-04-21]. DOI: 10.1016/j.joen.2020.03.008. ISSN 00992399.

5. Gorbalenya AE, Baker SC, Baric RS et al. The species Severe acute respiratory syndromerelated coronavirus: classifying 2019-nCoV and naming it SARS-CoV-2. Nat Microbiol 2020. https: //doi.org/10.1038/ s41564-020-0695-z.

6. Wax RS, Christian MD. Practical recommendations for critical care and anesthesiology teams caring for novel coronavirus (2019-nCoV) patients. Can J Anaesth 2020. https: //doi.org/10. 1007/s12630-020-01591-x. Accessed 18 March, 2020.

7. Sohrabi C, Alsafi Z, O'Neill N et al. World Health Organization declares global emergency: a review of the 2019 novel coronavirus (COVID-19). Int J Surg 2020; 76: 71-76.

8. WHO director-general's opening remarks at the media briefing on COVID-19 - 3 March 2020. Available at: https://www.who.int/dg/speeches/detail/who-director-general-s-opening-remarks-at-the-media-briefingon-covid-19 - 3-march-2020. Accessed 11 March, 2020.

9. Situation Report-91 SITUATION IN NUMBERS total and new cases in last 24 hours. Available at: https: //www.who.int/docs/defaultsource/coronaviruse/situation-reports/20200430-sitrep-101-covid-19. pdf?sfvrsn=2ba4e093_2.

10. Hlavaty T, Krajcovicova A. Novel unorthodox strategies to reduce the case fatality rate of COVID-19 in high risk groups including patients using ace inhibitors. Bratisl Med J [online]. 2020 [cit. 2020-04-21]. DOI: 10.4149/BLL_2020_74.

11. Wax RS, Christian MD. Practical recommendations for critical care and anesthesiology teams caring for novel coronavirus (2019-nCoV) patients. Can J Anaesth 2020. https: //doi.org/10.1007/s12630-020-01591-x. Accessed 18 March, 2020.

12. Lan L, Xu D, Ye G et al. Positive RT-PCR test results in patients recovered from COVID-19.JAMA 2020. https: //doi.org/10.1001/ jama.2020.2783.

13. Guan W, Ni Z, Hu Y et al. Clinical characteristics of 2019 novel coronavirus infection in China. medRxiv. Available at: https: //www.medrxiv. org/content/10.1101/2020.02.06.20020974v1. Accessed March 11, 2020.

14. Wu Z, McGoogan JM. Characteristics of and important lessons from the coronavirus disease 2019 (COVID-19) outbreak in China: summary of a report of 72314 cases from the Chinese Center for Disease Control and Prevention. JAMA 2020. https: //doi.org/10.1001/jama.2020.2648.

15. Rothe C, Schunk M, Sothmann P et al. Transmission of 2019-nCoV infection from an asymptomatic contact in Germany. N Engl J Med 2020; 382: 970-971. 


\section{2-716}

16. Giacomelli A, Laura Pezzati L, Conti F et al. Self-reported olfactory and taste disorders in SARSCoV-2 patients: a cross-sectional study, Clinical Infectious Diseases, ciaa330, https: //doi.org/ 10.1093/cid/ciaa330.

17. Centers for Disease Control and Prevention. Infection control: severe acute respiratory syndrome coronavirus 2 (SARS-CoV-2). Available at: https: //www.cdc.gov/coronavirus/2019-ncov/infection-control/controlrecommendations.html. Accessed 9 March, 2020.

18. Eggers M, Koburger-Janssen T, Eickmann M, Zorn J. In vitro bactericidal and virucidal efficacy of povidone-iodine gargle/mouthwash against respiratory and oral tract pathogens. Infect Dis Ther 2018; 7: 249-259.

19. Peng X, Xu X, Li Y et al. Transmission routes of 2019-nCoV and controls in dental practice. Int J Oral Sci 2020; 12: 9.

20. Kariwa H, Fujii N, Takashima I. Inactivation of SARS coronavirus by means of povidone-iodine, physical conditions, and chemical reagents. Jpn J Vet Res 2004; 52: 105-112.

21. Kampf G, Todt D, Pfaender S, Steinmann E. Persistence of coronaviruses on inanimate surfaces and its inactivation with biocidal agents. J Hosp Infect 2020; 104: 246-251.

22. List N. EPA's registered antimicrobial products for use against novel coronavirus SARS-CoV-2, the cause of COVID-19. Washington, DC: United States Environmental Protection Agency. Available at: https: //www. epa.gov/pesticide-registration/list-n-disinfectants-use-against-sarscov- 2 . Accessed March 18, 2020.
23. van Doremalen N, Bushmaker T, Morris DH et al. Aerosol and surface stability of HCoV-19 (SARS-CoV-2) compared to SARS-CoV-1. N Engl J Med 2020 March 17. https: //doi.org/ 10.1056/NEJMc2004973.

24. Hokett SD, Honey JR, Ruiz F et al. Assessing the effectiveness of direct digital radiography barrier sheaths and finger cots. J Am Dent Assoc 2000; 131: 463-467.

25. "Immunity passports" in the context of COVID-19 24 April 2020 Evidence brief Avaiable at: https: //www.who.int/news-room/commentaries/detail/immunity-passports-in-the-context-of-covid-19.

26. Wölfel R, Corman VM, Guggemos W et al. Virological assessment of hospitalized patients with COVID-2019. Nature 2020.

27. To KK, Tsang OT, Leung WS et al. Temporal profiles of viral load in posterior oropharyngeal saliva samples and serum antibody responses during infection by SARS-CoV-2: an observational cohort study. Lancet Infect Dis 2020 Mar 23. pii: S1473-3099(20)30196-1. DOI: 10.1016/ S1473-3099(20)30196-1.

28. Wu F, Wang A, Liu M et al. Neutralizing antibody responses to SARSCoV-2 in a COVID-19 recovered patient cohort and their implications. medRxiv 2020: 2020.03.30.20047365.

29. Hatala R. Proposal for complementary targeted public health antiepidemic measures during the pandemics of COVID-19. Bratisl Med J [online]. 2020 [cit. 2020-04-21]. DOI: 10.4149/BLL_2020_76. ISSN 1336-0345. 